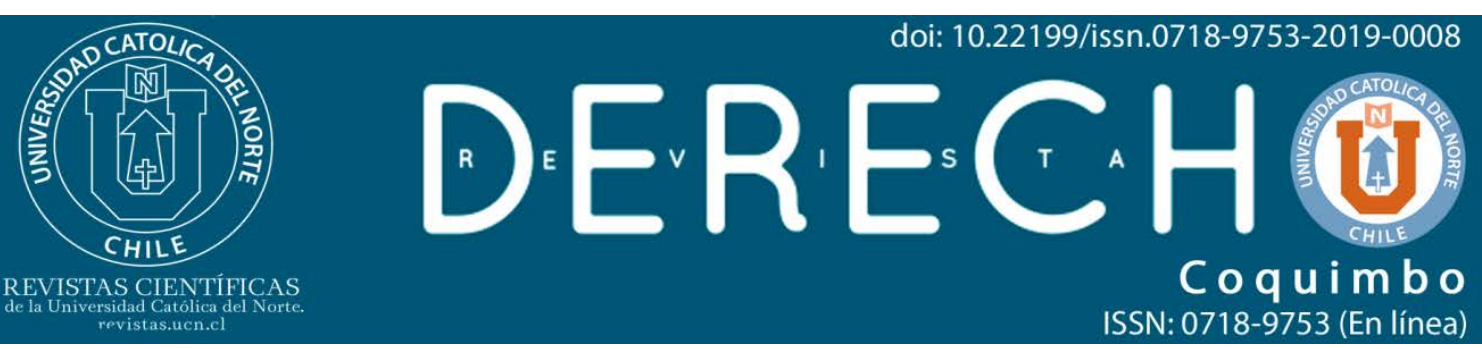

\title{
La configuración del desistimiento del consumidor
}

\section{The configuration of consumer withdrawal}

\author{
Francisca Barrientos Camus* \\ Íñigo De la Maza Gazmuri**(D) https://orcid.org/0000-0001-6239-2837 \\ "Universidad Adolfo Ibáñez, Santiago, Chile.Profesora adjunta. francisca.barrientos@edu.uai.cl \\ *Universidad Diego Portales, Santiago, Chile. Profesor. inigo.delamaza@udp.cl
}

\section{Resumen:}

Este trabajo tiene dos objetivos orientados en torno al derecho de desistimiento del consumidor en la Ley de Protección de los Derechos de los Consumidores. El primero de ellos consiste en, acreditar la existencia de un derecho de desistimiento del consumidor en esta norma. El segundo -y el que desarrollamos con mayor extensión- consiste en establecer la fisonomía -es decir los requisitos de procedencia- de este derecho.

Palabras Clave: Consumo; Contratos por adhesión; Desistimiento; Desahucio; Revocación.

\begin{abstract}
:
This paper has two objectives related to the consumer's right of withdrawal in the Chilean Consumer Rights Protection Law. The first objective consists of demonstrating the existence of a consumer's right of withdrawal in the Chilean consumer law. The second objective -and the one that will be developed to a greater extent- consists of establishing its properties, more specifically, the requirements for admissibility and cause of action of this right.

Keywords: Consumption; Standard form contracts; Withdrawal; Unilateral termination; Revocation.
\end{abstract}




\section{Introducción}

El desistimiento es una forma de ponerle fin a los contratos, mediante un acto libre y voluntario, que no tiene que fundarse en una causa (Díez Picazo, 2008, p. 1086). Este derecho se basa en la prohibición de la perpetuidad de las relaciones obligatorias y el interés contractual.

Para Caprile Biermann (2011) primer autor nacional que ha examinado este tema, es "... una forma de extinción del contrato que consiste en la facultad concedida por la ley o por la convención a una o ambas partes para romper unilateralmente el contrato, por su sola voluntad, sin necesidad de un incumplimiento de la contraria, bastando su ejercicio de buena fe y noticiarla con un preaviso razonable a la contraria, so pena de indemnizar los perjuicios en caso de ejercicio irregular" (p. 271) ${ }^{1}$.

El Código Civil lo recoge de forma fragmentada en una serie de instituciones. No obstante lo anterior, la doctrina lo ha configurado como un derecho de carácter general o principio aplicable a una serie de contratos, más allá de su dispersión legal (Pizarro Wilson, 2007, p. 12).

Y si se considera que la declaración unilateral de voluntad tiene mérito suficiente para dar por finalizada la relación contractual antes del tiempo previsto (Rodríguez Guitián, 2001, p. 684)², a partir de reglas fraccionadas que disciplinan la contratación libremente discutida, en que las partes asumen los mismos poderes de negociación y de información, que no cuentan con prescripciones tuitivas especiales, cabe preguntarse si es posible configurarlo para las relaciones regidas por la Ley No 19.496 sobre protección de los derechos de los consumidores, en que el legislador ha silenciado esta posibilidad. Este es el primer objetivo de esta presentación.

Entonces, como la ley no consagra un desistimiento de carácter general aplicable a todos los contratos (tampoco lo hizo el Código Civil) acudiremos a algunas normas generales y otras disposiciones especiales (financieras) de la propia Ley de Protección de los Derechos de los Consumidores que permitirían incorporarlo. También emplearemos las reglas del derecho común.

\footnotetext{
${ }_{1}^{1}$ Antes, en materia de arrendamiento se dijo que "es la noticia anticipada que una de las partes da a la otra de su deseo de poner término al contrato", en Piedrabuena Richard (1972, p. 101); o "... una comunicación dada por uno de los contratantes con el objeto de expresarle su voluntad de ponerle término al contrato", en Zaldívar Larraín (1958, p. 34).

2 Definición tomada de sus estudios, donde el autor analiza el desistimiento de los profesionales liberales en el derecho español.
} 
Así las cosas, en las líneas que siguen intentaremos configurar el derecho a desistimiento del consumidor o usuario ${ }^{3}$, a partir de una mirada al Código Civil y lo dispuesto en la Ley 19.496 (art. 16, a)).

Una prevención antes de comenzar. Nuestro estudio del desistimiento unilateral no considerará el "retracto" regulado en la Ley 19.496 (art. 3 bis). Su texto es el siguiente: "El consumidor podrá poner término unilateralmente al contrato en el plazo de 10 días contados desde la recepción del producto o des de la contratación del servicio y antes de la prestación del mismo, en los siguientes casos...".

La razón por la cual hemos decidido prescindir de su tratamiento es que, según creemos, no se trataría de una clase de desistimiento unilateral ad nutum, propio de los contratos de ejecución duradera que consideraremos. Por otra parte, siguiendo las ideas de Beluche Rincón (2009, p. 28), podemos decir que el retracto y el desistimiento tienen una serie de diferencias, así el retracto tiene un fundamento diverso, puesto que opera con efecto retroactivo, es gratuito y se entrega durante un período breve. En cambio, el desistimiento opera con efecto prospectivo y no tiene plazo de caducidad. Por lo demás, la distinción que proponemos entre desistimiento y retracto parece tener acogida en el ámbito nacional ${ }^{4}$.

\section{La admisibilidad de un derecho de desistimiento en la Ley de Pro- tección de los Derechos de los Consumidores}

\subsection{Una mirada a la admisibilidad del derecho de desistimiento en el de- recho común}

Como se ha expuesto con anterioridad, nuestro Código Civil recoge el derecho de desistimiento en una serie de disposiciones fragmentadas. En efecto, ellas se encuentran en las normas que regulan el "desahucio" del contrato de arrendamiento de cosas (art. 1951) o servicios (arts. 1999 y 2005)5; la "revocación" que realiza el mandante o la "renuncia" del mandatario contemplados en los arts. 2164, 2165 y 2167 del Código Civil; la "renuncia" de los socios en el art. 2108; la "revocación" por ingratitud en las donaciones ex art. 1428, el "retracto" del fiador dispuesto en el art. 2339, entre otras (Caprile Biermann, 2011, p. 278) ${ }^{6}$.

\footnotetext{
${ }^{3}$ Pese a las diferencias que existen entre ellos (véase art. $1 \mathrm{~N}^{\circ} 1$ ), desde ahora en adelante se toman como sinónimos

${ }^{4}$ Para Prado López (2013, pp. 155-157) y Pinochet Olave (2013, pp. 172 y 173) este retracto se encontraría en la etapa de formación del consentimiento.

${ }^{5}$ También se encuentra regulado en la Ley 18.101(art. 3).

${ }^{6}$ Agrega, además, el caso del depósito dispuesto en el Código Civil (art. 2226)que regula la restitución del depositario cuando se ha pactado una cláusula que establezca el tiempo de la devolución; las restituciones anticipadas del comodato en el Código Civil (arts. 2180 y 2177); el pago anticipado de las 
Como lo explica Caprile Biermann (2011, p. 272) ${ }^{7}$, el hecho que el desistimiento no cuente con una regulación sistemática en el Código no ha impedido la configuración del derecho general potestativo ${ }^{8}$. Así, este autor aboga por el reconocimiento de un principio general que autorice a los contratantes a desistirse unilateralmente de un contrato. En su concepto, solo sería posible admitir una excepción al pacta sunt servanda en los contratos de duración indefinida, cuando no existe una norma legal que lo autorice o pacto que lo permita, porque las partes no pueden quedar obligadas a perpetuidad. De este modo, configura el desistimiento en los contratos a plazo indefinido por analogía iuris y a través del estudio de sus requisitos; misma técnica que emplearemos para atribuirle este derecho al consumidor (Caprile Biermann, 2011 , p. 273,278 y ss.).

Por su parte, Severín Fuster (2017) reconoce la existencia general de este derecho en los contratos de servicios ad nutum, es decir, sin necesidad de justificarlo mediante una causa determinada. Para promoverlo ofrece una serie de razones. Primero, la incorporación de ciertas "bases normativas" en los contratos de servicios que regula el Código (supra arrendamiento, mandato, depósito, etc.). Junto con ello, considera que es razonable tratarlo dogmáticamente como un derecho que le asiste a una parte del contrato, pero no lo concibe como un remedio del cliente. Y, tercero, para favorecer el equilibrio contractual, reconoce que este derecho a desistirse está sujeto a una serie de deberes o cargas.

En España, Díez Picazo (2008, pp. 1084, 1086-1088) advierte la tensión que existe entre el arbitrio de dejar a una de las partes la subsistencia del contrato y que una vinculación obligatoria sea perpetua. Por eso, recalca que existe un principio general contra la perpetuidad de las relaciones jurídicas. Así, el desistimiento o denuncia se erige como el mecanismo en virtud del cual, cualquiera de las partes puede poner fin al contrato de tiempo duradero, mediante un acto libre y espontáneo, que no tiene que fundarse en una causa especial.

obligaciones de dinero del muto ex art. 2204 Código Civil; junto con las arras de la compraventa en el Código Civil (art. 1802); y que regula la posibilidad de "arrepentirse" en el arrendamiento (Código Civil, art. 1921).

${ }^{7}$ Existe una deuda dogmática con el estudio sistemático de la terminación del contrato. Este hecho se advierte por la terminología multiforme y fragmentada que gira en torno a ella (v. gr. mutuo disenso, resolución, terminación, resciliación, nulidad, revocación, imposibilidad en la ejecución, muerte entre las partes, el plazo extintivo). Esta advertencia también la habían efectuado tiempo atrás Alessandri Rodríguez, Somarriva Undurraga y Vodanovic Haklicka (1998), al expresar que "hemos visto, en nuestro Código y en otros extranjeros [que] este desistimiento recibe nombres heterogéneos y equívocos (desahucio, revocación, renuncia unilateral)" (p. 117) Misma problemática que enfrenta el derecho español que cuenta con desistimientos, revocaciones, renuncias o denuncias. Un panorama de ello ofrecen, entre otros, Díez Picazo (2008 p. 1086); Beluche Rincón (2009, pp. 23-24).

${ }^{8}$ Antes, en nuestro medio Córdova Bustos (1960, p. 31) formuló un intento de sistematización de la revocación de los actos jurídicos en el ámbito patrimonial y sucesorio. Define revocación como un acto jurídico unilateral y arbitrario que tiene por objeto privar de efectos, en todo o parte, a un acto anterior. Con todo, no reconoce un derecho general, más allá de los supuestos establecidos en la ley. 
Klein (1997, pp. 27,28 y 140) reafirma la idea de evitar relaciones contractuales a perpetuidad, reconociendo que el desistimiento sería la forma común de extinción, similar al cumplimiento, en los contratos duraderos. Misma idea que defiende Rodríguez Guitián (2001, p. 684), quien reconoce la existencia de este derecho en los contratos de servicios indefinidos, pero centra sus estudios en los contratos de duración determinada. E, incluso, en el ámbito del consumo, Álvarez Moreno (2000, p. 388) ${ }^{9}$, defiende el derecho a desistimiento en la contratación por adhesión con consumidores, precisamente, por la extensión de los vínculos jurídicos. Así, a falta de una regla expresa, considera que "en este ámbito contractual [consumo] se proyecta la construcción clásica del Código Civil sobre el desistimiento, fundamentada en que nadie puede obligarse eternamente".

Bianca (2007, p. 761-763) ha señalado que se trata de un poder negocial para interrumpir la relación contractual, cuyo fundamento se basa en el interés objetivo de la parte en terminar el vínculo obligatorio, con el límite de la buena fe. Incluso, lo hace aplicable a falta de una provisión legal específica, aunque el Codice civile (art. 1373) cuenta con una regulación genérica ${ }^{10}$.

Larroumet (1993, p. 162) expresaba que habría una "enajenación de libertad" 11 si no se admitía la "resiliación unilaeral" (Klein, 1997, p. 124) en los contratos de duración indeterminada. Por eso, lo concibe como la regla general en estos contratos, pero aplicándole las limitaciones de la buena fe. Ahora el Code (art. 1211) lo regula de forma expresa ${ }^{12}$.

En definitiva, a partir de estas voces autorizadas es posible advertir que la contratación duradera tiene como límite las relaciones a perpetuidad, y que detrás de la construcción dogmática del desistimiento del contrato se trata de evitar una especie de "enajenación de la libertad" o voluntad de las partes contratantes.

\footnotetext{
${ }^{9}$ Aun cuando sienta su estudio en la cláusula abusiva de terminación unilateral.

10 "Se a una delle parti è attribuita la facoltà di recedere dal contratto, tale facoltà può essere esercitata finché il contratto non abbia avuto un principio di esecuzione (2). Nei contratti a esecuzione continuata o periodica (3), tale facoltà può essere esercitata anche successivamente, ma il recesso non ha effetto per le prestazioni già eseguite o in corso di esecuzione (4). Qualora sia stata stipulata la prestazione di un corrispettivo per il recesso (5), questo ha effetto quando la prestazione è eseguita. $\dot{E}$ salvo in ogni caso il patto contrario"

${ }^{11}$ La prohibición de la perpetuidad puede analizarse desde la perspectiva de la libertad contractual (perpetuidad subjetiva) o bien como una limitación a la propiedad (perpetuidad objetiva).

${ }^{12}$ Lorsque le contrat est conclu pour une durée indéterminée, chaque partie peut y mettre fin à tout moment, sous réserve de respecter le délai de préavis contractuellement prévu ou, à défaut, un délai raisonnable.
} 
Con estos antecedentes, veamos si es posible traspasar estos requisitos al ámbito de las condiciones generales de la contratación ${ }^{13}$ celebradas con consumidores. Antes de eso, conviene hacerse cargo de lo regulado en Ley 19.496 (art. 16, a).

\section{2. ¿Constituye el artículo 16 a) de la Ley de Protección de los Derechos de los Consumidores un obstáculo al reconocimiento del desistimiento en las relaciones de consumo?}

El artículo 16 literal a) de la Ley de Protección de los Derechos de los Consumidores dispone que: "No producirán efecto alguno en los contratos de adhesión las cláusulas o estipulaciones que: a) Otorguen a una de las partes la facultad de dejar sin efecto...".

Por la redacción de esta norma, hay que decir que la doctrina más autorizada ya había cuestionado la disposición española de la cual se extrajo este literal, considerándola "absurda" (Bercovitz Rodríguez-Cano, 1987, p. 205) ${ }^{14}$. Aunque de manera menos sanguínea, la doctrina nacional, parece compartir la resistencia de la española frente a la literalidad del precepto en cuestión, señalando que una interpretación que favorezca al consumidor impide concluir que se prohíben las cláusulas que permiten a éste el desistimiento (Caprile Biermann, 2011, pp. 273-275) ${ }^{15}$.

En realidad, la adecuada interpretación del precepto indica que lo que realmente se prohíbe es el establecimiento de cláusulas abusivas de término unilateral del proveedor; es decir, de aquellas estipulaciones predispuestas por esta persona que le permiten dar término al contrato sin una notificación previa o suficiente antelación. Así, lo sostienen Caprile Biermann (2011, p. 273-274), Momberg (2014, p. 177 y ss.), Pizarro Wilson y Petit Pino (2013, p. 305-306) y Rosas Zambrano (2014, pp. 254$255)^{16}$.

Pues bien, tomando en consideración sus argumentos, creemos que la interpretación de la letra a) del artículo 16 que prohíbe el desistimiento unilateral del consumidor es absurda, no sólo porque teleológicamente no tiene sentido hacerlo en

\footnotetext{
${ }^{13}$ Se usan como sinónimos contratos por adhesión y contratación por adhesión, aunque la Ley de Protección de los Derechos de los Consumidores sólo define los segundos (vid. art. 1 №6).

14 "La defensa contractual del consumidor y el reparto de competencias entre el Estado y las comunidades autónomas en la doctrina del tribunal constitucional". El artículo 10.1 de la antigua ley española sobre defensa de los consumidores y usuarios de 1984 prohibía las cláusulas o condiciones o estipulaciones contrarias a la buena fe y justo equilibrio. En su numeral 2 recogía: "Las cláusulas que otorguen a una de las partes la facultad de resolver discrecionalmente el contrato, excepto, en su caso, las reconocidas al comprador en las modalidades de venta por correo, a domicilio y por muestrario".

${ }^{15}$ Reconoce la existencia de este derecho para el consumidor. Para ello toma como base lo dispuesto en la Ley 19.496 (art. 16, a).

${ }^{16}$ Disentimos con su opinión sobre los contratos con cláusulas de renovación automáticas, nosotros lo estimamos como indefinidos.
} 
una ley tutelar de los derechos de los consumidores, sino porque, además, la misma ley lo permite tratándose de contratos que disciplinen productos y servicios financie$\operatorname{ros}^{17}$.

Por estas razones, y para finalizar esta parte, conviene destacar que el derecho de desistimiento se construye en el derecho común para los contratos de ejecución duradera, porque, simplemente, el derecho no tolera el establecimiento de vínculos jurídicos a perpetuidad. Con ello, se trata de evitar la "enajenación de la libertad" de las partes contratantes. De allí que se haya propuesto que el desistimiento sería la forma común de ponerle término a estos contratos, al asimilarlo a las formas de cumplimiento de las obligaciones. $Y$, si se toma en consideración estas ideas, fuerza reconocer que estos contratos tienen una especial fisonomía, dada por la extensión de sus prestaciones, que exigen considerar otras formas de término alejadas de las categorías tradicionales de extinción de las obligaciones (Código Civil, art. 1567).

Así, la verdadera pregunta no es si procede el derecho de desistimiento para el consumidor en los contratos por adhesión de ejecución duradera en los términos de la Ley 19.496 (art. 16, a), sino que bajo qué condiciones procedería; y esta es la principal tarea de este trabajo, a la cual dedicamos la segunda parte.

\section{Los requisitos del derecho de desistimiento en la Ley de Protec- ción de los Derechos de los Consumidores}

El consumidor tendrá derecho a desistirse de los contratos por adhesión que contengan obligaciones duraderas en el tiempo, siempre y cuando manifieste su voluntad, ofreciendo un preaviso y que este derecho se ejerza de buena fe.

Sin embargo, antes de examinar estos requisitos, conviene justificar las "bases normativas" del derecho común, que permitirán identificar las condiciones que necesita el consumidor para ponerle término de forma unilateral al contrato por adhesión.

\subsection{Algunas cuestiones preliminares}

Primero, resulta importante considerar que la mayoría de los contratos de adhesión con consumidores establecen duraciones a plazos determinados prorrogables de forma automática y sucesiva por el mismo período de tiempo ${ }^{18}$. Por eso, sería

\footnotetext{
${ }^{17}$ En efecto, el art. 17 D inc. 3 establece: "Los consumidores tendrán derecho a poner término anticipado a uno o más servicios financieros por su sola voluntad y siempre que extingan totalmente las obligaciones con el proveedor asociadas al o los servicios específicos que el consumidor decide terminar, incluido el costo por término o pago anticipado determinado en el contrato de adhesión".

${ }^{18}$ En efecto, estudios de la Academia de Derecho y Consumo de la Fundación Fernando Fueyo han detectado en el mercado de telecomunicaciones que los contratos de suministro de servicio tienen 
posible sostener que dichos contratos se transformarían en vínculos jurídicos dura$\operatorname{deros}^{19}$.

Segundo, como se sabe, el contexto de las relaciones de consumo es especial. En estos casos, se establece de forma ejemplar un catálogo de derechos irrenunciables de forma anticipada para el consumidor (art. 4) ${ }^{20}$; existen una de serie de deberes precontractuales de información tipificados en la ley ${ }^{21}$ (arts. 1 № 3, 3 letra b] 32, etc.); la publicidad se integra de forma expresa al contrato ${ }^{22}$ (art. $1 \mathrm{~N} \times 4$ ); se establecen controles de forma (art.17) ${ }^{23}$ y de fondo (art. 16) (Momberg Uribe y Pizarro Wilson, 2013) de los contratos por adhesión. Y no está demás señalar que estos sujetos no son meros compradores o prestatarios de los bienes y servicios, sino que personas contratantes que gozan de derechos con reconocimiento constitucional (v. gr. la no discriminación arbitraria) ${ }^{24}$.

Por eso, si bien asumimos que existen particularidades de ley de consumo, a la vez estamos de acuerdo con Baraona González (2014, pp. 382, 384 y 386) ${ }^{25}$ en que

\footnotetext{
una duración de 12 meses. Pero, le agregan una cláusula de prórroga de forma indefinida por períodos sucesivos, salvo un caso que expresa que su contrato tiene duración indefinida. En el área bancaria ocurre una situación similar en el sentido que los contratos de cuenta corriente contemplan un plazo de un año renovable automáticamente por períodos iguales. Las empresas de retail utilizan en sus contratos la modalidad de plazo indefinido y se establecen las causales que dan a lugar el término del contrato. Véase para telecomunicaciones, Barros Vergara, Domínguez Riffo, Figueroa, Impellizzeri, y Portugal (2016) ; para sector financiero Alvarado Mualme, M., Cortéz López, H., Cortés Solís, C., Duguet Vergara, R., Emilfork Orthusteguy, M., Muñoz Fuentes, I., Zuazo Echeñique, A. (2016); Específicamente sobre el retail, De la Maza Gazmuri, Í (2007).

${ }^{19}$ En estos contratos se verifica que el objeto principal es la realización de un comportamiento continuo en el tiempo, que durante todo ese período tiene un carácter solutorio. No se trata de prestaciones periódicas, aplazamiento o fragmentaciones de la prestación. El servicio se debe realizar de forma continua y constante durante el tiempo contratado, en Díez Picazo (2008, p. 519).

${ }^{20}$ Espada Mallorquín (2013, p. 194), explica que la finalidad que tiene la norma del artículo 4 es el establecimiento de un mínimo de protección invulnerable que le asegure para todos los actores de la relación de consumo un nivel de certeza jurídica.

${ }^{21}$ Como explica De la Maza Gazmuri (2010, pp. $22-29$ y 2013, p. 24) dentro de las relaciones de consumo se presenta un esquema de desigualdad entre las partes, razon por la cual se vuelve necesario establecer normas que busquen establecer un equilibrio dentro de estas relaciones desigualitarias.

${ }^{22}$ Se ha explicado la publicidad se integra al contrato cuando los elementos objetivos de las emisiones, esto es, los de carácter informativo que contenga la publicidad, son: 1) releventantes a la hora de contratar y 2) razonablemente confiable, en De la Maza Gazmuri (2013b, pp. 39-45).

${ }^{23}$ Se pretende establecer normas de trasparencia y claridad, que más allá de ser un control de cláusulas abusivas, persiga que el consumidor esté o pueda estar en conocimiento de su situación jurídica, comprendiendo de forma clara a que está obligado y sin tener dudas respecto de cuáles son sus derechos, en Pizarro Wilson y Pérez López (2013, pp. 361-362).

${ }^{24}$ En este sentido, Alvear Téllez $(2016$, p. 820) propone tres ámbitos de concurrencia de los derechos subjetivos del consumidor con la protección constitucional de la libertad económica, con el fin de abogar por una concepción relacional del derecho del consumidor, descartando una noción conflictiva. El tercero se relaciona con las normas imperativas que rigen al contrato de consumo, los derechos fundamentales y el orden público económico.

${ }^{25}$ Propone que el bien superior ya no sería asegurar la clásica libertad de contratación, sino proteger el acto de consumo masivo, a partir de la confianza que le ha suscitado la propuesta del proveedor.
} 
el derecho constituye el marco supletorio de la Ley de Protección de los Derechos de los Consumidores.

Entonces, como la mayoría de las relaciones contractuales duraderas que celebran los consumidores califican como prestaciones de servicios, y aunque se califiquen -con razón- de inadecuadas e insuficientes las disposiciones civiles que lo disciplinan ${ }^{26}$, hay que reconocer que, al menos, algunas reglas del arrendamiento (Caprile Biermann, 2011, p. 277); (Severín Fuster, 2015) y mandato ${ }^{27}$ se aplicarían de forma supletoria al ámbito de los consumidores. Entre ellas, las que toleran el término unilateral de una de las partes cuando se pierde interés en mantener el vínculo obligacional.

El contrato de arrendamiento, por su naturaleza duradera o indefinida, invita a dejar atrás la contratación a perpetuidad para el consumidor. Y, en el caso del mandato, coincidimos con Severín Fuster (2017, p. 4) en que más de hablar de confianza entre las partes, la revocación que regula este contrato se funda simplemente en el interés de la parte, tal como parece suceder con la contratación por adhesión celebrada con consumidores, en que no se encuentran buenas razones para mantener al consumidor obligado a perpetuidad si ha perdido interés en el contrato y con menor razón se puede hablar del intuitus personae.

No emplearemos las disposiciones del contrato de la sociedad, porque entendemos que ellas se alejan de la relación de consumo. Tampoco utilizaremos las reglas contenidas en el comodato o en la donación, ya que, en principio, la gratuidad las excluiría de la Ley de Protección de los Derechos de los Consumidores ${ }^{28}$; ni de las arras reguladas en la compraventa porque este derecho nace en los contratos de ejecución duradera o indefinida. Respecto de la fianza, el depósito y el mutuo, que se aplican en materia de consumo, no las utilizaremos, porque por su fisonomía de obligaciones de garantía regulan una clase de retracto de obligaciones futuras (art. 2329) y restituciones anticipadas (arts. 2226 y 2204), que no dicen relación con la caracterización del desistimiento unilateral del consumidor que intentamos configurar.

Sin embargo, el hecho de que nos sirvamos de algunos contratos típicos no significa que creamos que únicamente procede el desistimiento en ellos u otros que puedan asimilarse por la proximidad de su contenido. El estudio del derecho común

\footnotetext{
${ }^{26}$ En este sentido, Brantt Zumaran y Mejías Alonzo (2016, pp. 75 y 77) lo califican como un contrato atípico, al que de forma supletoria se le aplican las reglas del mandato y del arrendamiento, pero con una serie de particularidades respecto de qué reglas aplicar, si priman unas sobre otras y sus efectos..

${ }^{27}$ Barros Bourie (2012, pp. 330-331) advierte que no todas las reglas del mandato se aplican analógicamente a las prestaciones de servicios, porque no en todos los contratos de servicios hay encargos 0 relaciones fiduciarias, pero si sería posible hacerlo cuando se deben cumplir deberes de custodia y cuidado. Caprile Biermann (2011, p. 277).

${ }^{28}$ Recordemos que, a pesar de las críticas que se le han formulado, el consumidor es quien celebra un acto jurídico oneroso (art. 1 №1) y el proveedor el que cobra un precio o tarifa (art. 1 №2).
}

Rev. derecho (Coquimbo, En línea) 2019, 26: e3589 
sobre contratos nos muestra otra cosa. En este sentido, Caprile Biermann (2011, p. 288), quien en esto sigue a Díez Picazo (2008, pp. 840-841), considera que es posible admitir un derecho a poner término unilateral al contrato fuera de los casos permitidos por la ley, siempre que se reúnan los siguientes requisitos: $1^{\circ}$ debe existir una relación jurídica obligatoria duradera o de tracto sucesivo o que no tenga previsto un plazo de duración temporal (indefinida); $2^{\circ}$ la parte que se desistirá debe manifestar su voluntad; $3^{\circ}$ debe hacerlo mediante un anuncio o preaviso; y $4^{\circ}$ debe ejercerlo de buena $\mathrm{fe}^{29}$. Al amparo de sus estudios, consideramos que esos mismos requisitos se aplican en materia de consumidores ${ }^{30}$.

\subsection{Primer requisito: el contrato por adhesión debe ser de ejecución du- radera $o$ indefinida}

Para que se aplique el desistimiento del consumidor se requiere ausencia de plazo en el contrato por adhesión o que se pacte un vínculo obligacional indefinido.

Sobre la forma de analizar la implicancia de esta regla hemos decidido sistematizar este estudio en dos partes,

\subsubsection{La ejecución duradera o indefinida a partir del derecho común}

El desahucio sólo será pertinente "si no se ha fijado tiempo para la duración del arriendo" (Código Civil, art. 1951). En el caso de los servicios inmateriales, el Código entrega esta facultad en los servicios que consisten en una larga serie de actos (artículos 2009 y 2007).

De estas disposiciones se infiere que el contrato puede ser de ejecución duradera, tractos sucesivos o indefinidos ${ }^{31}$, porque se reconoce la posibilidad que estos vínculos no tengan un tiempo de duración.

Junto con ello, es posible observar la relación que existe con el tiempo. En las relaciones duraderas el tiempo es especial ${ }^{32}$, porque hay una continua satisfacción

\footnotetext{
${ }^{29}$ Caprile Biermann (2011, p. 288), deja de lado el carácter intuitu personae de algunos contratos para configurar el desistimiento en los negocios jurídicos indefinidos.

${ }^{30}$ No creemos que se requiera la existencia de justa causa para desahuciar. En el derecho civil español Klein (1997, pp. 60-63) es partidario de esta opción, pero en materia civil común sin referirse a consumidores. Nuestras normas civiles, en especial en lo que dice relación con el arrendamiento y el mandato no lo contemplan. Junto con ello, la regulación que contempla la Ley de Protección de los Derechos de los Consumidores, al menos en materia financiera, tampoco.

${ }^{31}$ A partir de ahora le llamaremos duradero también a los vínculos a tractos sucesivos o indefinidos.

${ }^{32}$ Andrés Bello consideraba que "El tiempo es un elemento de tanta consecuencia en las relaciones jurídicas, y ha dado motivo a tantas divergencias en las decisiones de las judicaturas y en la doctrina de los jurisconsultos, que no se ha creído superfluo fijar reglas uniformes, a primera vista minuciosas, para determinar
} 
del interés contractual. Y, precisamente, por ese tiempo y los intereses de las partes, ciertos elementos de la relación obligacional se tornan "más intensos", como los deberes emanados de la buena fe y cierta clase de derechos potestativos, como el desistimiento (Klein, 1997, p. 71).

Por otra parte, hay que decir que las facultades unilaterales en la contratación son excepcionales. La regla general es que las partes no puedan poner término unilateralmente a los contratos. Así lo ha sostenido en nuestro país, entre otros López Santa María (2010, p. 274-278) ${ }^{33}$, a propósito de su estudio sobre la fuerza obligatoria de los contratos. Pero, en estos contratos, como no se ha fijado un tiempo determinado de duración, se entrega un derecho unilateral para extinguirlo en cualquier momento, justificado en la idea de que no pueden existir obligaciones indefinidas ${ }^{34}$, la prohibición de la perpetuidad (Caprile Biermann, 2011, p. 287) o enajenación de la libertad.

Por eso, en realidad, si se proyectan las obligaciones en el tiempo, como lo sugiere Peñailillo Areválo (2003), será posible advertir que las obligaciones o contratos de ejecución duradera o de tracto sucesivo las obligaciones son "transitorias"; en sus palabras: "...cuando en las obligaciones de ejecución duradera no se ha señalado plazo de vigencia, por diversas razones se suele conferir a los vinculados la facultad de terminarlas unilateralmente (en algunas situaciones como el arriendo se le ha asignado el nombre de desahucio). Al deudor, destacadamente debido a aquella característica de la obligación que hemos denominado transitoriedad conforme a la cual la obligación es un vínculo eminentemente transitorio (y a que coarta la libertad del obligado). Al acreedor, por diversas razones derivadas de la naturaleza de la obligación unida a su carácter de duradera" (pp. 340 y 350). Como en otras cosas, éste autor lleva razón respecto a que la transitoriedad caracteriza a las obligaciones y se opone a que resulten perpetuas para alguna de las partes.

Para reforzar esta idea, conviene citar las palabras de Díez Picazo (2008) que expresa "la perpetuidad es opuesta a la naturaleza misma de la relación obligatoria. Constituyendo ésta, desde el punto de vista del deudor, una limitación de la libertad, tal

el punto preciso en que nacen y expiran los derechos y las obligaciones en que este elemento figura", en Mensaje del Código Civil.

${ }^{33}$ Este autor advierte que, en ciertos casos, resulta perfectamente lícita la terminación unilateral y pone como ejemplo -entre otros el desahucio en los arrendamientos a plazo indefinido, incluso Caprile Biermann (2011, p. 273) señala que el catálogo de casos en que resulta posible poner término unilateralmente a un contrato es vastísimo. En ocasiones lo autoriza así explícitamente el legislador y, en otros casos, no existe dicha regulación, no obstante se acepta ampliamente la posibilidad del término unilateral.

${ }^{34}$ Así, Alessandri Rodríguez, Somarriva Undurraga y Vodanovic Haklicka (2004, p. 73) señalaban que los vínculos pueden tener mayor o menor duración, pero siempre son eminentemente temporales, ya que toda obligación limita la libre actividad del deudor en alguna medida porque este debe encaminar una parte de su hacer a cumplir la prestación y, un vínculo que impusiera en forma permanente semejante limitación sería odioso y, en el hecho, atentaría contra la plena libertad del individuo.

Rev. derecho (Coquimbo, En línea) 2019, 26: e3589 
limitación, si fuera perpetua, debería ser considerada como contraria al orden público"( $p$. $566)^{35}$. En sentido similar, Rodríguez Guitián (2001) comenta que "No parece haber obstáculos en admitir el desistimiento en los contratos duraderos en general con duración indeterminada [...] El desistimiento encuentra su fundamento en la inconveniencia de mantener indefinidamente a las partes vinculadas y además no puede decirse que sea una idea extraña en nuestro ordenamiento" (p. 684) ${ }^{36}$.

Entonces, detrás del amparo de la revocación, terminación unilateral o desahucio -como quiera llamarse ${ }^{37}$ - en el contrato de arriendo se encuentra la idea de "interés contractual y razonabilidad de término" como lo ha expuesto Severín Fuster (2017, p. 7) o "precariedad inicial" que tiene el vínculo contractual, en palabras de Cornejo Aguilera (2012, p. 255). En efecto, las partes analizarán en el tiempo la continuidad o no de su relación contractual conforme a los intereses que se generen.

De allí que el contrato no pueda ser perpetuo, sino transitorio, porque una facultad de ese tipo pugnaría contra la protección de la libertad contractual. Incluso, si se quisiera aplicar la tesis de Díez Picazo (2008) en nuestro país, habría que verificar la posibilidad de configurar una hipótesis de ineficacia por contrariar el orden público (artículos 1461 y $1466^{38}$ ), en este caso, económico. Y como el orden público económico ${ }^{39}$ encuentra su máxima regulación en la Constitución, no ha de extrañar la presencia de recursos de protección interpuestos por cuentacorrentistas que intentan fundamentar la "arbitrariedad" de la decisión tomada por los bancos al intentar

\footnotetext{
35 "Ello equivale a decir que en tales casos las partes disponen de una facultad de denuncia o de receso de la relación obligatoria. Aunque semejante facultad no se encuentra reconocida con carácter general dentro del sistema de nuestro Derecho Positivo, puede encontrar su fundamento en la idea de la imposibilidad de mantener indefinidamente vinculadas a las partes y, además, en el hecho de que constituye una regla muy extendida en todas aquellas relaciones obligatoria que suponen una vinculación indefinida...".

${ }^{36}$ Ver además Klein (1997, p. 16).

${ }^{37}$ Ya habíamos denunciado la falta de una nomenclatura unitaria que reúna en un supuesto la facultad de terminación unilateral del contrato (supra nota 10).

${ }^{38}$ Si bien, el artículo 1466 Código Civil no contempla de forma expresa esta causal, a diferencia de lo que sucede en materia de causa ilícita (Código Civil, art. 1467), Alessandri Besa (2008, p. 141) consideró la contravención al orden público integraría una de las causales especiales de objeto ilícito (Código Civil, arts. 1462 a 1466). En sus palabras dichas causales se dividen: "a) por haber ejecutado el acto o celebrado el contrato contraviniendo la ley, las buenas costumbres o el orden público, o bien b) Por recaer el consentimiento de las partes sobre una cosa que se encuentra fuera del comercio, siempre que el acto importe enajenación de ella". Y dentro de la expresión que emplea el artículo 1466 Código Civil "todo contrato prohibido por las leyes" incluyó los actos que contravengan las buenas costumbres o el orden público. Por su parte, Claro Solar (2013, p. 237) consideró que en el artículo 1461 Código Civil se encontraba la regla general en materia de objeto. Y esta disposición se complementaba con el artículo 1466 Código Civil, que contempla la causal genérica de objeto ilícito: los actos o contratos prohibidos por la ley. Por eso, conectó la contravención al orden público con el objeto ilícito, al expresar que "Por lo demás, la prohibición del acto o contrato por la ley tiene generalmente como fundamento las buenas constumbres contra las cuales pugna dicho acto o contrato, o razones de orden e interés público que han llevado al legislador a establecer la prohibición".

${ }^{39} \mathrm{El}$ orden público económico es entendido como el "conjunto de principios y normas jurídicas que organizan la economía de un país y facultan a la autoridad estatal para regularla en armonía con los valores de la sociedad nacional formulados en la Constitución", en Cea Egaña (1988, p. 158).
} 
desistirse de los contratos ${ }^{40}$, o de asegurados que se ven afectados por el término unilateral arbitrario de las compañías de seguros ${ }^{41}$.

$\mathrm{Y}$ respecto del contrato de mandato no se habla de plazo o tiempo de duración. Las disposiciones contenidas en los art. 2163 No3 y N4 Código Civil suponen que cualquiera de las partes puede revocar el contrato. Como decíamos, Severín Fuster $(2017$, p. 9$)$ lo funda en el interés de la parte y el objeto del contrato.

Pues bien, la regla que se extrae a partir de estas normas y sus interpretaciones es que tratándose de contratos de duración indefinida, se encuentra implícita la facultad de ponerles término de forma unilateral. Esto permite que se potencie la libertad de las partes, sin alterar el orden público.

Todas estas ideas pueden integrarse a los contratos por adhesión de duración indefinida o duradera celebrados con consumidores, tema que analizaremos a continuación.

\subsubsection{La ejecución duradera o indefinida en la Ley de Protección de los Dere- chos de los Consumidores}

Como se ha expuesto en el apartado anterior, en el derecho común la facultad de ponerle término unilateral al negocio se encuentra implícita en todos los contratos de duración indefinida.

\footnotetext{
40 Una línea de fallos rechaza la arbitrariedad de los bancos al estimar la existencia de depósitos inusuales provenientes del extranjero, sin justificarlo. Así en Virgilio Cartoni Maldonado y otros con Banco Bilbao Vizcaya Argentaria Chile (2017), el Banco señaló que el cierre de cuentas se adoptó tras un proceso de análisis de la situación del cliente que evidenció una serie de depósitos en las cuentas corrientes por montos sustancialmente superiores a los ingresos declarados, transferencias desde el extranjero que procedían de empresas acusadas de cometer delitos de soborno y lavado de activos, y por haberse recibido órdenes de pago al exterior carentes de justificación (cons. 5). En Intervalores Corredores de Bolsa Ltda. con Banco Bilbao Vizcaya Argentaria Chile (2017) el Banco recurrido alegó que utilizó legítima y fundadamente la facultad regulada y autorizada por la Superintendencia de Bancos e Instituciones Financieras, pactada en el contrato y que además emana del carácter indefinido e intuito personae del contrato de cuenta corriente. Asimismo, señala que no se pueden alegar infringidos artículos de la Ley de Protección de los Derechos de los Consumidores, porque la recurrente es una sociedad mercantil, no un consumidor. (cons. 5). En Nicolás Fischman Rajii con Banco BBVA (2016), el recurrido sostuvo que estaba habilitado para poner término en forma unilateral y en cualquier tiempo a lo pactado, aduciendo que el recurrente no había proporcionado antecedentes que se ajustaran a la realidad respecto de los montos de los depósitos de su cuenta corriente, que eran muy superiores a sus ingresos mensuales según los registros del Banco (cons. 5).

${ }^{41}$ En esta línea se encuentra, por ejemplo, María Teresa García Vallejo contra Compañía de Seguros Penta Vida (M) (2014), en que se declaró arbitrario el cierre del contrato de parte de la compañía aseguradora al considerar que este contrato se rige por la ley de consumo y el art. 16, a) prohíbe los términos unilaterales. Así "En otras palabras, es ilegal la decisión de la recurrida de poner fin a la cláusula Adicional de Prestaciones Médicas 'Cobertura de Salud Segunda Vida Ejecutivo' desde el momento que la disposición contractual que la facultaba para obrar del modo que lo hizo carece de toda eficacia" (cons. 8).
} 
Por eso, ahora se trata de saber si la regulación de las relaciones de consumo mantiene esta característica o, en cambio, la modifica.

En principio, podría pensarse que como estas relaciones no se basan en la libertad contractual, sino que en la defensa del acto de consumo y la protección de la transparencia (Baraona González, 2014, pp. 382 y 384), sólo cabrían formas de desistimiento estipuladas en una cláusula predispuesta. Pensamos que la atención no debe centrarse en este aspecto.

En realidad, sería posible sostener que en este ámbito también se detectan relaciones de ejecución duradera o indefinida. Por eso, sería posible afirmar la protección de la libertad contractual, aunque no con el mismo rigor que en la contratación civil (Baraona González, 2014, p. 388) ${ }^{42}$. Por la configuración especial de las relaciones indefinidas y la prohibición de la perpetuidad de los vínculos jurídicos, resulta necesario configurar un derecho de desistimiento a favor del consumidor. De manera que si aceptamos que el contratante civil puede desistirse de un contrato antes de tiempo tan sólo manifestando su voluntad, a fortiori debiésemos alcanzar la misma conclusión respecto de un consumidor si el contrato por adhesión no lo contempla o la ley no lo autoriza expresamente.

Además, hay que tomar en consideración que este derecho no sólo se funda en la enajenación de la libertad de las partes, sino que en el resguardo de sus intereses. Y, precisamente esta es la finalidad tuitiva de la Ley de Protección de los Derechos de los Consumidores, al intentar equiparar sus posiciones por las asimetrías que enfrentan. En este sentido, Rosas Zambrano (2014, p. 255), sostiene que hay que reconocer que los intereses del consumidor van rotando en el tiempo, sin que pueda pensarse que este sujeto se encuentra obligado a permanecer en el contrato de manera indefinida.

Con todo, para reafirmar lo que se viene diciendo corresponde examinar algunas las disposiciones de la ley que permitirían inferir la existencia de este derecho en la contratación duradera.

Así, el art. 12 de la ley, puede colaborar en la construcción de este derecho. La disposición señala "Todo proveedor de bienes o servicios estará obligado a respetar los términos, condiciones y modalidades conforme a las cuales se hubiere ofrecido o convenido con el consumidor la entrega del bien o la prestación del servicio". Nasser Olea (2013, p. 258), comentando esta disposición, ve en ella una manifestación del pacta sunt servanda. Y si ello es así, he aquí otro argumento para aceptar el término unilateral del contrato por parte del consumidor, toda vez que el fundamento de esta dis-

\footnotetext{
${ }^{2}$ A su vez Momberg Uribe (2012, p.247) reconoce una fuerza innovadora del Derecho del Consumo para justificar la alteración de los principios tradicionales del derecho común.
} 
posición coincide con la libertad civil en orden a evitar relaciones a perpetuidad. De este modo, la Ley 19.496 (art. 12), al obligar a respetar lo pactado, se inspiraría en la libertad de los contratantes ${ }^{43}$; misma libertad que le permitiría al consumidor desahuciar el contrato de forma anticipada en aquellas obligaciones de ejecución duradera o indefinida cuando ha perdido el interés.

Por otra parte, a partir de lo dispuesto en el art. 12 de la ley, aflora otra cuestión que está íntimamente relacionada con la construcción del desistimiento del consumidor: la existencia de cláusulas abusivas de término unilateral predispuestas por el proveedor. De manera que si el proveedor intenta limitar o restringir el derecho de desahucio del consumidor, conforme se interpreta el art.16, a), estaríamos en presencia de una cláusula abusiva. Ejemplos de ellas se encuentran en el ámbito educacional, cuando algunos centros intentaron dejar sin efecto el contrato, como Alvarado Uribe, Jorge Armando con Universidad Católica del Norte Coquimbo. $1^{\circ} \mathrm{Jdo}$ Policía Local de Coquimbo (2013) ${ }^{44}$ o Servicio Nacional del Consumidor con Corporación Universidad de Aconcagua (UAC) (2013) ${ }^{45}$, aunque huelga decir que se invocó como causal para hacerlo el rendimiento académico de los alumnos/as. Por ello, en realidad, estimamos que en estos casos la argumentación judicial resultó discutible, ya que no parecían arbitrarias estas cláusulas. De todas formas, si el empresario condiciona la permanencia del contrato a la aceptación forzosa de un alza de precio so pena de terminar el contrato, como sucedió en el caso Servicio Nacional del Consumidor con Cencosud Administradora de Tarjetas S.A. (2013), no cabe duda la abusividad. $\mathrm{Y}$, además, se puede objetar que el empresario se arrogue de forma unilateral y arbi-

\footnotetext{
${ }^{43}$ Pero matizada, Baraona González (2014) "No se trata ya de proteger la pura libertad contractual, en el sentido de asegurar libertad a la espontánea decisión de contratar, sino de garantizar a los consumidores que los bienes y servicios que se les ofrecen podrán adquirirlos, o servirse de ellos, en los términos que ellos están siendo ofrecidos, que no serán sometidos a condiciones inicuas, que se les respetarán las condiciones y modalidades ofrecidas, que no serán dañados daños o menoscabados, entre otras cosas, y en general no serán sometidos a prácticas comerciales desleales" (pp. 385-386).

${ }^{44}$ La cláusula en entredicho expresaba "La Universidad hace expresa reserva de poner término a este contrato en cualquier momento, cuando a su exclusivo juicio determine que el rendimiento académico del estudiante no le permite continuar con el contrato". Y aunque esta cláusula sujeta el término del contrato al rendimiento académico del alumno/a, por lo que podría discutirse su supuesta arbitrariedad, la Corte de sentenció "Que, resulta incuestionable que la cláusula décima del contrato encuadra perfectamente en la descripción de la norma legal transcrita..." (cons. 17).

${ }^{45}$ Se sentenció "Que como puede verse, siempre será abusiva una cláusula que permita a una de las partes dejar sin efecto el contrato, cuyo es aquí el caso, se haya o no pactado para ello alguna determinada condición, porque confiere además un derecho desproporcionadamente favorable para el proveedor, provocando un desequilibrio importante en los derechos y obligaciones de las partes [...] Es por eso que todos los argumentos expuestos por el recurrente, acerca que la cláusula no es abusiva en atención a razones ecónomicas y pedagógicas o porque no depende de su solo arbitrio sino que de un hecho externo que no está entregado a la voluntad de la Universidad, sino que de la voluntad del público en general, no pueden ser oídos desde que simplemente la cláusula será abusiva si le permite la facultad de dejar sin efecto el contrato ..." (cons. 6). No compartimos las razones de este fallo, menos la interpretación que negaría el desistimiento del consumidor.
} 
traria la facultad de prorrogar el contrato de forma indefinida sin contemplar este derecho para el consumidor, porque habría un peligro de perpetuidad ${ }^{46}$.

Junto con ello, consideramos que esta disposición debe complementarse con el derecho irrenunciable que le asiste al consumidor para informarse de forma veraz y oportuna sobre las "condiciones de la contratación" consignadas en el art. 3, b). Dichas "condiciones de la contratación"47, para los efectos del tema que estamos estudiando, serían la ejecución duradera o indefinida del vínculo obligacional y la debida información que debe suministrar el proveedor del derecho que le asiste al consumidor para revocar el contrato, en cualquier momento y sin expresión de causa alguna y de buena fe.

Regla que, en materia financiera ${ }^{48}$, cuenta con directrices especiales de información ${ }^{49}$, transparencia y simplicidad. En efecto, los literales b) y c) del art. 17B contemplan algunas formas de término unilateral del contrato.

Nos interesa analizar el art. 17B literal c) que reconoce un deber especial de informar: "la duración del contrato o su carácter de indefinido o renovable automáticamente, las causales, si las hubiere, que pudieren dar lugar a su término anticipado por la sola voluntad del consumidor".

Muchas dudas nos deja la redacción de esta norma, porque estaría condicionando el ejercicio del derecho a la inclusión que haga el proveedor de esta facultad ${ }^{50}$.

\footnotetext{
${ }^{46}$ En este sentido, Klein (1997, p. 132).

${ }^{47}$ Por ejemplo, Barrientos Zamorano (2013, pp. 102-103) menciona la incorporación de personas al contrato, el crédito educacional.

${ }^{48}$ El ámbito de aplicación financiero comprende "los contratos de adhesión de servicios crediticios, de seguros $y$, en general, de cualquier producto financiero, elaborados por bancos e instituciones financieras o por sociedades de apoyo a su giro, establecimientos comerciales, compañías de seguros, cajas de compensación, cooperativas de ahorro y crédito, y toda persona natural o jurídica proveedora de dichos servicios o productos" (art. 17B primera parte).

${ }^{49}$ Sobre los deberes precontractuales de información y la importancia que tienen para el consumidor pueden consultarse los estudios de De la Maza Gazmuri (2006) y (2010, pp. 21-52).

${ }^{50}$ Con todo, no podemos dejar de mencionar que una regla similar se estableció para el proveedor, en la ley española del crédito al consumo. En efecto, se permite que el prestamista deje sin efecto el contrato "si así lo pactado en el contrato de crédito". La Ley 16/2011, establece: "1. El consumidor podrá poner fin gratuitamente y en cualquier momento, por el procedimiento habitual o en la misma forma en que lo celebró, a un contrato de crédito de duración indefinida, a menos que las partes hayan convenido un plazo de notificación. El plazo de preaviso no podrá exceder de un mes. 2. Si así ha sido pactado en el contrato de crédito, el prestamista podrá poner fin por el procedimiento habitual a un contrato de crédito de duración indefinida dando al consumidor un preaviso de dos meses como mínimo, notificado mediante documento en papel o en otro soporte duradero. 3. Si así ha sido pactado en el contrato de crédito, el prestamista podrá, por razones objetivamente justificadas, poner fin al derecho del consumidor a disponer de cantidades de un contrato de crédito de duración indefinida. El prestamista informará al consumidor de la terminación del contrato, indicando las razones de la misma mediante notificación en papel u otro soporte duradero, en la medida de lo posible antes de la terminación y, a más tardar, inmediatamente después de ella. No se comunicará la información a que se refiere el párrafo anterior cuando su comunicación esté prohibida por una norma de la Unión Europea o sea contraria a objetivos de orden público o de seguridad
} 
Lamentamos que no existan vestigios de ella en la historia fidedigna de su establecimiento ${ }^{51}$. Y, además, que no exista, a la fecha de publicación de este artículo, algún trabajo que se haga cargo de esta situación en el medio nacional.

A pesar de lo anterior, sólo se sabe que ella contiene un deber especial de informar el término unilateral del contrato del consumidor financiero, intentando disminuir las asimetrías que suelen caracterizar las relaciones entre proveedores y consumidores, favoreciendo una elección más libre de los bienes y servicios (De la Maza Gazmuri, 2013, p. 24). ${ }^{52}$.

Sin embargo, al parecer, en este caso no se cumpliría esa directriz, ya que la norma sugiere que las causales de término del consumidor estarán dispuestas en el contrato si el proveedor las contempla.

Por eso, cuesta comprender la técnica empleada, ya que la norma obliga a informar las causales de término anticipado del consumidor "si las hubiere".

La expresión "si las hubiere" insinuaría la posibilidad de abolir la existencia de este derecho al permitirle al prestador financiero agregarlas o no al contrato, con independencia de la naturaleza del vínculo obligacional (ejecución duradera o indefinida).

No puede hacerse una lectura de este tipo ${ }^{53}$, porque un proveedor no podría excluir el desistimiento del consumidor en los contratos financieros de ejecución duradera. Una cláusula de ese estilo sería abusiva conforme lo dispone el artículo 16 letra a) de la ley. Por eso, fuerza decir que la disposición comentada sólo establece un deber de información para el proveedor financiero, nada más.

pública. 4. Si se hubiera suscrito un contrato de seguro accesorio al de crédito, el contrato de seguro se extinguirá al mismo tiempo que éste y el consumidor tendrá derecho al reembolso de la parte de prima no consumida" (art. 27).

${ }^{51}$ Estas causales, y todo el artículo 17B, se incorporaron por una Indicación del Ejecutivo, de fecha 01 de octubre, 2010. Oficio en Sesión 84. Legislatura 358, en el Primer Trámite Constitucional en la Cámara de Diputados (Biblioteca del Congreso Nacional, 2019)

${ }^{52}$ De la Maza Gazmuri (2013, p. 24). Hernández Paulsen (2015).

${ }^{53}$ No hay mayores antecedentes sobre esta norma, menos sobre la expresión "si las hubiere". Se sabe que en el proyecto original se hablaba de "causales legales", pero al parecer fueron mal entendidas en la discusión parlamentaria. En este sentido, "El Jefe de la División Jurídica del Ministerio de Economía, señor Eduardo Escalona, recordó que el proyecto original del Ejecutivo no se limitaba solamente a especificar las causales legales de término, pero en el debate de la Comisión de Economía se consideró útil incorporar la restricción, pues de otra manera implicaba una apertura amplia para que el oferente, redactor del contrato, establezca un sinnúmero de causales legales de terminación que no son necesariamente las exigidas en el mercado financiero", Informe de las comisiones de economía y de hacienda, unidas... (2011). Por otra parte, hay que señalar que hubo una Indicación del Senador Navarro que establecía "Los consumidores tendrán derecho a poner término anticipado a uno o más servicios financieros por su sola voluntad, en la medida que se trate de contratos de duración indefinida", pero no tuvo consenso, Segundo informe de la comisión de economía (2011).

Rev. derecho (Coquimbo, En línea) 2019, 26: e3589 
Junto con ello, hay que recordar que el art. $17 \mathrm{D}$ inc. 3ero consagra la existencia del desistimiento propiamente tal, sin establecer ninguna limitación respecto de las causas (causales si las hubiere). Esta disposición señala que: "Los consumidores tendrán derecho a poner término anticipado a uno o más servicios financieros por su sola voluntad y siempre que extingan totalmente las obligaciones con el proveedor asociadas al o los servicios específicos que el consumidor decide terminar, incluido el costo por término o pago anticipado determinado en el contrato de adhesión".

Como se lee, ella reafirma la existencia del derecho de desistimiento del consumidor. La ley lo trata como un derecho, que opera por la sola voluntad del consumidor financiero, sin expresión de causa. Y gracias a ello, se puede desahuciar toda clase de contratos financieros. La existencia de este derecho, junto con la aplicación general y supletoria del derecho común que prohíbe la contratación a perpetuidad, hace posible la configuración de un desistimiento general.

Si bien, esta regla no habla de forma expresa sobre el tipo de contrato en que opera, sabemos que puede ejercerse en las relaciones jurídicas obligaciones duraderas o perpetuas, precisamente porque no distingue.

¿Qué podemos concluir del artículo 17 B literal c)? Nuestra impresión es que, tanto la finalidad tuitiva de la Ley de Protección de los Derechos de los Consumidores como el derecho a poner del consumidor a término anticipado a uno o más servicios financieros por su sola voluntad indica que lo que debe informar el proveedor es si "hubiera" un derecho de desistimiento establecido en condiciones más ventajosas que el que la ley establece irrenunciablemente para el consumidor.

\subsection{Segundo requisito: el consumidor debe manifestar la voluntad de desistirse}

En esta parte examinaremos la necesidad que el consumidor manifieste voluntad de ponerle fin al contrato. Y este análisis lo realizaremos con la misma técnica empleada con anterioridad, esto es, distinguiendo entre la manifestación de voluntad del desahucio a partir del derecho común y luego la manifestación de voluntad del desahucio en la Ley de Protección de los Derechos de los Consumidores.

\subsubsection{La manifestación de voluntad del desahucio a partir del derecho común}

El desahucio es el aviso anticipado que hace una de las partes de su voluntad de terminar contrato.

En el contrato de arrendamiento no existe una regla precisa sobre la manifestación de la voluntad de desistirse del contrato. Por eso, Caprile Biermann (2011, p. 
291), sostiene que aunque se haya pactado en este contrato una forma especial de notificación, como una certificación, si ella no se verifica siempre será posible la terminación del contrato.

En el contrato de mandato, el mandante puede revocar el mandato "a su arbitrio" (art. 2165). Para Stitchkin Branover y Figueroa Yáñez (2012) esto significa que este sujeto no necesita fundar su decisión, encontrar alguna causa o siquiera "justificar faltas o abusos del mandatario". Puede hacerlo en cualquier tiempo y cualquier lugar, sea o no remunerado este contrato, de forma expresa o tácita (art. 2164). Y produce sus efectos desde que el mandatario ha tenido conocimiento del acto (art. 2165). Esto muestra que se trata de un acto jurídico unilateral recepticio, pues el Código Civil ha exigido que la voluntad del mandante produzca efectos desde que llega a conocimiento mandatario. Stitchkin Branover y Figueroa Yáñez (2012, p. 469) es claro en señalar que este conocimiento no asume ninguna formalidad especial, puede darse de palabra, por escrito, carta o cualquier medio que demuestre el conocimiento de la parte.

Por su parte, el mandatario puede "retractarse" mientras se halle en aptitud de ejecutar el negocio por sí mismo (art. 2124), pero esta "renuncia" y cualquier otra que realice con posterioridad tendrá efectos después de transcurrido el tiempo razonable para el mandante pueda proveer a los negocios encomendados (art. 2167). Lo anterior evidencia, que también estaríamos frente a negocios jurídicos recepticios. Como lo reconoce Stitchkin Branover y Figueroa Yáñez (2012, p. 474) es un acto unilateral, por consiguiente no es necesario que el mandante lo acepte.

Un punto interesante, que sirve de contraste con la ley, es que el Código Civil y el de Comercio (art. $241^{54}$ ) toleran la estipulación de irrevocabilidad del encargo conferido al mandatario, salvo que se trate de un mandato general de administración de bienes. La Ley de Protección de los Derechos de los Consumidores prohíbe la irrevocabilidad de los mandatos, al menos en materia financiera ex art. 17B, g) y art. $17 \mathrm{l}$.

En suma, todas las disposiciones reseñadas muestran la existencia de una manifestación de voluntad que puede caracterizarse como un acto jurídico unilateral ${ }^{55} \mathrm{y}$ recepticio ${ }^{56}$, cuyos efectos jurídicos están destinados a privar de efectos a un negocio existente. En algunos casos, como el mandato, se reconoce hasta la pertinencia de la revocación tácita.

\footnotetext{
${ }^{54}$ El comitente no puede revocar a su arbitrio la comisión aceptada, cuando su ejecución interesa al comisionista o a terceros

${ }^{55}$ En materia de revocación, Domínguez Águila (2012, p. 234); Alessandri Rodríguez, Somarriva Undurraga y Vodanovic Haklicka (1998, p. 351).

${ }^{56}$ Caprile Biermann (2011, p. 291); Díez Picazo (2008, p.1088); Bianca (2007, p.762).

Rev. derecho (Coquimbo, En línea) 2019, 26: e3589
} 
Asimismo, es necesario señalar que el Código Civil no considera la existencia de una causa justificada para que sea procedente esta institución. De hecho, en materia de arrendamiento no se requiere expresar motivos para desahuciar. La regla es clara en el mandato, en que se ha dicho que el mandante puede revocar el mandato "a su arbitrio" (art. 2165). Y Stitchkin Branover y Figueroa Yáñez (2012) han señalado que "El mandatario que renuncia no necesita explicar ni fundar su resolución" (p. 474).

Así las cosas, a partir del derecho común, sabemos que las partes pueden dejar sin efecto estos contratos de forma unilateral manifestando su voluntad. Se requiere, entonces, la existencia de un negocio jurídico unilateral que pretenda desahuciar el contrato.

Ahora corresponde examinar cómo se trasladan estas directrices generales al ámbito de la ley.

\subsubsection{La manifestación de voluntad del desahucio en Ley de Protección de los Derechos de los Consumidores}

En lo que dice relación con la manifestación de voluntad del consumidor, esta normativa ha sido bastante parca.

Incluso, hasta hoy, se discute la admisión de la aceptación tácita del consumidor. De todas formas, se ha expresado que sí podría tener cierta cabida en las relaciones con consumidores. Y en general, los argumentos se relacionan con la aplicación de las reglas del Código de Comercio, que otorgan igual valor a la aceptación expresa y tácita, cuidando eso sí el cumplimiento de las prescripciones especiales de la ley de consumo ${ }^{57}$.

Baraona González (2014) ha precisado la forma en que operaría la aceptación tácita, opinando que "Ellas no podrán admitirse con tanta amplitud como en el derecho común, pues, pueden esconder abusos, en el sentido de que el consumidor no ha conocido exactamente la propuesta que está aceptando. Incluso más, la misma disposición permite rechazar la posibilidad de que el consumidor pueda ser compelido por el proveedor, de que su no expresión se tendrá como aceptación o desistimiento [...] Por lo mismo, las aceptaciones tácitas, como la que acabo de referir están severamente restringidas en

\footnotetext{
${ }^{57}$ Tapia Rodríguez (2014) señala: "Desde ya debe tenerse presente que en el derecho privado nacional la aceptación tácita está sujeta a las mismas reglas y produce los mismos efectos que la aceptación expresa artículo 103 del Código de Comercio). Si bien es una regla que se encuentra en el Código de Comercio, en ausencia de una regulación sistemática de la formación del consentimiento en el Código Civil, se ha estimado que tales reglas suplen este vacío y forman parte del Derecho Común. Por su parte, la LPDC al no contener reglas expresas al respecto, debe interpretarse a la luz de ese derecho común" (p. 58). y Barrientos Camus (2014) considera que: "El consentimiento en los contratos por adhesión puede prestarse de forma expresa o tácita. Ambos tienen el mismo valor y producen los mismos efectos" (p. 47).
} 
el derecho de consumo"(p. 388-389) ${ }^{58}$. Así, entendemos que, para éste autor, lo importante es que se demuestre que el consumidor ha podido conocer "exactamente qué está aceptando". Y aunque esto sería difícil de determinar en la práctica, por la regla del silencio y por la configuración misma de los actos y contratos de consumo, habría que encontrar aquellos elementos que mostrarían que el consumidor quiso (fue informado y conocía) de forma inequívoca -facta concludentia- los efectos del acto jurídico que se trata de aplicar.

En relación al tema que nos convoca, tenemos que afirmar que la revocación debe ser manifestada por el consumidor. Es de esperar que su voluntad se exteriorice de forma expresa, para evitar inconvenientes con el ámbito de aplicación de la aceptación tácita y su distinción con el silencio, aun cuando sea en su propio beneficio.

Para estos efectos, conviene recordar que la expresión "a su solo arbitrio" empleada por el art. 16, a) no ayuda en la construcción de este derecho. Ella refiere, más bien, a sancionar las conductas del proveedor que sean contrarias a la razón o dependiente de su solo capricho (Pizarro Wilson y Petit Pino, 2013, p. 308), o integrando esta regla con el art. 16, g), puede considerarse que la arbitrariedad sería lo contrario a la buena fe (Barrientos Camus, 2016).

Al menos para las materias financieras, el legislador consideró la existencia de este requisito. En efecto, el art.17D, inc. 3 considera que el consumidor puede ponerle término "... a uno o más servicios financieros por su sola voluntad...". La expresión a su sola voluntad lo contemplaría. Pero tampoco se señalan las formas de hacerlo. En España, en materia financiera se menciona que debe hacerse por el procedimiento habitual o en la misma forma en que lo celebró ${ }^{59}$. Y esto tiene importancia para la determinación de las cláusulas abusivas, pues si el proveedor hace más gravoso el término del contrato debería ser sancionado ${ }^{60}$.

Por otra parte, la ley no ha dispuesto en las reglas generales que se informe con anterioridad la existencia de este derecho. Sí lo ha contemplado, aunque con una deficiente técnica legal, el art. 17B, c) en materia financiera, como se explicaba con anterioridad.

\footnotetext{
${ }^{58}$ La frase anterior expresaba "La manifestación de voluntad en los actos de consumo por parte del consumidor está sujeta a un importante restricción, entendiendo por silencio a la falta de expresión de voluntad, fundamentalmente por la vía del lenguaje, oral o escrito. En consecuencia, de la falta de manifestación o expresión de voluntad no puede derivarse aceptación del consumidor. La norma (art. 3 , a) tiene interés para los efectos de analizar la posible validez de aceptaciones tácitas, es decir, de aquellas que no se derivan de una explícita, clara e inequívoca manifestación de consentimiento por parte del consumidor...".

${ }^{59}$ Supra nota $\mathrm{n}^{\circ} 80$.

${ }^{60}$ Tal como ocurrió en Servicio Nacional del Consumidor con Cencosud Administradora de Tarjetas S.A. (2013)
} 
Tampoco se ha dicho en la ley si esta declaración es recepticia o no recepticia. Pero, podemos inferir, al menos para el ámbito financiero, y de allí extenderla a los demás contratos, que si el legislador ha querido que el proveedor informe los "plazos de aviso previo y cualquier costo por término o pago anticipado total o parcial que ello le represente" (art. 17D, inc. 3) será porque consideró que la voluntad del consumidor de desahuciar el contrato exige conocimiento del prestador.

Para finalizar, corresponde destacar una importante diferencia con las reglas del derecho común. El desahucio del consumidor no podrá ser irrevocable, con menor razón si se incorpora en una cláusula por adhesión predispuesta por el prestador, tal como ocurre "mandatos en blanco". En efecto, los mandatos en blanco, como se Ilaman en el tráfico, a juicio de San Martín Neira (2013, p. 405) se presentan cuando "a) cuando no señale en absoluto el encargo para el que ha sido conferido; b) cuando se trate de un mandato impreciso, que no especifique claramente el encargo al mandatario". Antes se discutía su validez (Caprile Biermann, 2013) ${ }^{61}$. Ahora se sancionan en materia financiera en la Ley 19.496 (art. 17B, g) y art. 17I), aunque con una técnica defectuosa. La primera norma establece "Se prohíben los mandatos en blanco y los que no admitan su revocación por el consumidor"; mientras que la segunda, que opera para la diputación al pago "...podrá dejar sin efecto dicho mandato, autorización o acto jurídico en cualquier tiempo".

Dicho esto, ahora corresponde explicar la forma en que opera el preaviso.

\subsection{Tercer requisito: el preaviso}

El tercer requisito para que el consumidor termine de forma unilateral el contrato es el preaviso. Y para seguir la misma sistemática que hemos examinado, veremos primero la configuración del preaviso a partir del derecho común, y luego la existencia del preaviso en la Ley de Protección de los Derechos de los Consumidores.

\subsubsection{El preaviso a partir del derecho común}

El preaviso es la noticia anticipada de la parte interesada de ponerle fin al contrato.

La institución del preaviso se encuentra recogida en diversas normas del Código Civil. En el arrendamiento, el art.1951 dispone que "si no se ha fijado tiempo para la duración del arriendo [... ninguna de las dos partes podrá hacerlo sino desahuciando a la otra". De manera que cualquiera de las dos partes del contrato puede desahuciar a la otra, noticiándoselo anticipadamente sino se ha fijado plazo en el contrato. Dicha

\footnotetext{
${ }^{61}$ González Castillo (2012).
} 
notificación se ajusta al período o tiempo de los pagos (art. 1951), con anticipación de un período entero (art. 1976) ${ }^{62}$. Incluso, opera si una de las partes goza del derecho y la otra no (art. 1953). Entonces, bajo las reglas generales del arrendamiento, el desahucio es un derecho extrajudicial que no requiere formalidades ${ }^{63}$, se fija por períodos de pago y opera para cualquiera de las partes.

En el mandato, la revocación del mandante produce efectos desde el día que el mandatario ha tenido conocimiento de ella (art. 2165), lo que indica la inexistencia de un preaviso para el mandatario. Sin embargo, no sucede lo mismo con la "renuncia" del mandatario, que será exigible una vez que haya transcurrido un tiempo razonable (art. 2167). Si bien, no se establece un plazo determinado parece adecuado ofrecer como criterio la razonabilidad, que se vincula con la buena fe.

Coincidimos con Caprile Biermann (2011, p. 293) en que la finalidad del preaviso es tuitiva. En este sentido, Díez Picazo (2008, p. 1088) enseña que la declaración de la denuncia debe ser hecha de buena fe. Y ella se concreta, a su juicio, en la necesidad de una prolongación de la relación durante un tiempo razonable. Todo ello, para que el co-contratante pueda adoptar las medidas necesarias que implica la extinción vínculo obligatorio. Pero es enfático en señalar que la violación de este principio no impide el desistimiento, sólo genera un deber de resarcir los daños. En el mismo sentido, Klein (1997) señala que: "la concesión de un preaviso se basa únicamente en consideraciones de equidad y ejercicio de buena fe del desistimiento; se trata de un instrumento que difiere el efecto extintivo, a fin de evitar perjuicios al contratante frente a quien se desiste" (p. 30).

De este modo, es posible deducir que el preaviso es necesario, pues la parte que pretende ponerle fin al contrato debe noticiar a su co-contratante, para que efectúe los resguardos y provisiones necesarios, porque este derecho ad nutum se concibe como herramienta de versatilidad de las relaciones comerciales, que se fija por el interés de la parte en el contrato, fundado en la prohibición de perpetuidad de las relaciones obligatorias. Por esa razón, el período de tiempo se ponderará por la medida de la razonabilidad o los períodos de pagos.

\footnotetext{
${ }^{62}$ Para los servicios inmateriales sino se ha estipulado el desahucio en el contrato el preaviso será de "medio período a lo menos" (art. 2009). Para los predios rústicos el Código Civil señala la siguiente regla "No habiendo tiempo fijo para la duración del arriendo, deberá darse el desahucio con anticipación de un año, para hacerlo cesar. El año se entenderá del modo siguiente: El día del año en que principió la entrega del fundo al colono, se mirará como el día inicial de todos los años sucesivos, y el año de anticipación se contará desde este día inicial, aunque el desahucio se haya dado algún tiempo antes. Las partes podrán acordar otra regla, si lo juzgaren conveniente".

${ }^{63}$ No ocurre lo mismo con el arrendamiento de bienes raíces urbanos que exige declaración judicial o notificación personal de un notario, cuando lo ejerce el arrendador; (Cornejo Aguilera, 2012, p. 255). No obstante lo anterior, Celis Rodríguez $(1982$, p. 29) considera que en la práctica siempre serían judiciales.
} 
La configuración del desistimiento del consumidor

Dicho eso, ahora corresponde examinar la configuración del preaviso en la ley.

\subsubsection{El preaviso en la Ley de Protección de los Derechos de los Consumidores}

Lo primero que debemos señalar que no existen normas generales que traten su existencia. La única disposición que lo menciona es el art. 17B, c), a propósito de las menciones que debe contener el contrato financiero, dentro los cuales se exige que aparezca "... las causales, si las hubiere, que pudieren dar lugar a su término anticipado por la sola voluntad del consumidor, con sus respectivos plazos de aviso previo...".

De todas formas, hay que advertir que el art. 17D, inc. 3 no hace referencia alguna al preaviso, por lo que podría considerarse que no sería necesario, más aún cuando éste se funda en una finalidad tuitiva para el consumidor. Pero, si se piensa, como deben extinguirse totalmente las obligaciones y pagarse una comisión especial de prepago, puede considerarse su existencia.

Como se ha explicado con anterioridad, el hecho que no aparezca en ninguna disposición general de la Ley de Protección de los Derechos de los Consumidores y sólo en las especiales financieras no nos impide reconstruirla, a partir de otras disposiciones.

Si el preaviso que debe realizar el consumidor se basa en consideraciones de buena fe, hay que mencionar el art. 16, g) que habla sobre ella. Y si bien, esta disposición contiene una regla general de abusividad contra el proveedor, nos puede servir en el sentido que no tolera en los contratos "un desequilibrio importante en los derechos y obligaciones que para las partes se deriven del contrato". En otras ocasiones se ha sugerido que "De la lectura del precepto es posible entender que lo exigido al proveedor es un trato leal y equitativo a su contraparte que tenga presente sus legítimos intereses. La buena fe constituye entonces un deber de conducta que se refleja en la forma en que el proveedor diseña y presenta el contenido del contrato por adhesión" (De la Maza Gazmuri, 2004, p. 52). Pero, además, nótese que la expresión que emplea el legislador es un equilibrio para "las partes" del contrato. Ahora este criterio mira el equilibrio jurídico o conmutatividad contractual (Momberg Uribe y Pizarro Wilson, 2013, p. 343). Para ello se atenderá a misma buena fe consagrada en el derecho común ${ }^{64}$.

\footnotetext{
${ }^{64}$ Así lo establecen Momberg Uribe y Pizarro Wilson (2013) al señalar que "Respecto a la primera cuestión no existe controversia que se trata de la denominada buena fe objetiva aludiendo a un comportamiento correcto o leal, sumado a las expectativas razonables que la confianza debe generar en el consumidor al momento de contratar. Es el mismo concepto desarrollado a propósito del artículo 1546 del Código Civil chileno" (p. 342).
} 
En este orden de ideas, si el legislador tolera la revocación contractual en determinados contratos, bajo ciertos requisitos y atendiendo la medida de la buena fe, que no es sino el fundamento detrás del preaviso, uno de los criterios que sirve para determinarla es el equilibrio contractual para las partes ex art. 16, g). Será, entonces, en virtud de esa reciprocidad obligacional que el consumidor deba avisarle al proveedor de su voluntad de desistirse del contrato, especialmente en el ámbito financiero en que se acelera el crédito y debe pagar la comisión de prepago.

A falta de un plazo determinado hemos de atender a la razonabilidad, tal como se ha dispuesto en la regla del mandato.

Para finalizar sólo cabe agregar algunas palabras sobre la concurrencia de la buena fe.

\subsection{Cuarto requisito: la buena fe}

Y para seguir la misma sistemática que hemos examinado, veremos primero la buena fe en el derecho común y luego la buena fe en la Ley de Protección de los Derechos de los Consumidores.

\subsubsection{La buena fe a partir del derecho común}

La buena fe es un principio reconocido en nuestro sistema. Y quizás, como lo advierte Klein (1997, p. 157), podría parecer ocioso hablar de ella en este apartado. Pero es necesario, porque como no existen reglas sistemáticas y uniformes que disciplinen el desistimiento debemos acudir a ella, para efectos de delimitar sus contornos.

En el mandato, se reconoce que el mandatario puede revocarlo "a su arbitrio". Caprile Biermann (2011, p. 290) reconocía que por sus especiales características el ejercicio de esta potestad no está sujeto al abuso del derecho.

Pero, en realidad las reglas que atienden a la renuncia de buena fe se encuentran referidas al contrato de sociedad. Y pese a que ellas no se consideran para la relación de consumo, a partir de estas reglas se podrán extraer, en esta parte, algunas directrices.

El Código Civil dispone "Renuncia de mala fe el socio que lo hace por apropiarse una ganancia que debía pertenecer a la sociedad; en este caso podrán los socios obligarle a partir con ellos las utilidades del negocio, o a soportar exclusivamente las pérdidas, si el negocio tuviere mal éxito. Podrán asimismo excluirle de toda participación en los beneficios sociales y obligarle a soportar su cuota en las pérdidas" (art. 2111). Como es posible observar de esta regla se infiere la proscripción de un ejercicio abusivo de la re- 
nuncia. Esto sería contrario a la buena fe objetiva que inspira a los contratantes. Si atendemos la disposición, es posible observar que la buena fe marca un criterio de tiempo, pero también cualitativo. En efecto, actúa de la mala fe el que pretende apropiarse de forma exclusiva de una ganancia social. Aquí, los perjudicados son los demás socios.

Se trata, entonces, de la buena fe objetiva, que nos permite advertir los límites y contornos del derecho potestativo. Por eso, hay que examinarla tomando en consideración un eventual perjuicio de la contraparte causada por la ruptura del vínculo jurídico. Para Bianca (2007, p. 762) se exige, entre otras cosas, que se resguarde el interés de la contraparte.

Para Klein (1997, p. 158 y 166) hay que procurar que "la ruptura del contrato sea lo menos traumática posible". Con ello, manifiesta que el sujeto que ejercita este derecho debe reducir o intentar eliminar los perjuicios que pueda sufrir su contraparte. Por ello, ve en esta parte, un deber de diligencia y precaución en el ejercicio del desistimiento.

Dicho eso, ahora corresponde mostrar los contornos que impone la buena fe en materia de consumo, tomando en consideración que se intenta configurar un desistimiento a favor de la parte menos informada y tutelada por la ley.

\subsubsection{La buena fe en la Ley de Protección de los Derechos de los Consumidores}

La facultad de ponerłe término al contrato debe ejercerse de buena fe, esto es, sin que la conducta constituya un ejercicio abusivo de su derecho.

Además de ser la buena fe un principio general del derecho $-y$, por lo mismo, sus exigencias predicables respecto de cualquier contratante-, nos parece que las sanciones que se establecen al consumidor que ejerza acciones y denuncias de forma temeraria (art. 50, E) ${ }^{65}$ y el derecho-deber de informarse responsablemente de sus derechos (art. 3, b) nos alertan de dichas exigencias en la Ley 19.496. Respecto del primero, Cortez Matcovich (2013, pp. 1004-1005), al comentar esta disposición, reconoce que se trata de un instrumento que tiende al equilibrio de las partes.

De todas formas, nos podemos servir del art. 16, g). Como lo hemos sostenido antes, esta disposición le prohíbe al empresario la incorporación de cláusulas abusivas, pero a partir de ellas se puedan extraer criterios generales, como que la buena fe también se le aplica al consumidor. Por eso, el estándar objetivo que concibe "un desequilibrio importante en los derechos y obligaciones que para las partes se deriven del

\footnotetext{
${ }^{65}$ Esta norma dispone que: "Cuando la denuncia, querella o demanda interpuesta carezca de fundamento plausible, el juez, en la sentencia y a petición de parte, podrá declararla como temeraria...".
} 
contrato" servirá para ofrecer algunos contornos a los límites del ejercicio de los derechos de los consumidores.

En definitiva, la buena fe del consumidor se concreta en el deber de preavisar, pero no impide el desistimiento del contrato; por eso se pide que la realización de conductas que supongan una conducta leal con su contratante.

\section{Conclusiones}

A partir de las reglas del derecho común se configura un derecho al desahucio a favor del consumidor.

Los requisitos serían la existencia de un contrato indefinido, de tractos sucesivos o ejecución duradera, el consumidor debe manifestar su voluntad de desahuciar el contrato, mediante un preaviso, y debe hacerlo de buena fe.

El art. 16, a) de la ley no prohíbe el desahucio del consumidor. Pensar lo contrario supondría avalar una interpretación literal que conduce a resultados extravagantes alejados de la debida protección que establece la ley. De allí que la recta interpretación del art. 16, a) de la Ley 19.496 deba ir por el camino de prohibirle al proveedor la incorporación de cláusulas abusivas de terminación unilateral arbitrarias.

\section{Agradecimientos}

Este artículo forma parte del proyecto FONDECYT de iniciación № 11140516, del cual la autora es responsable. Se agradece a los ayudantes Paula Godoy, Francisco Figueroa y Felipe Fernández por la búsqueda de materiales.

\section{Referencias Bibliográficas}

Alessandri Besa, A. y Wahl Silva, J. y Vodanovic Haklicka, A. (2008). La nulidad y la rescisión en el derecho civil chileno (3a ed., Vol. 1). Santiago: Editorial jurídica de Chile.

Alessandri Rodríguez, A., Somarriva Undurraga, M. y y Vodanovic Haklicka, A. (1998). Tratado de derecho civil. Partes preliminar y general (Vol. 2). Santiago: Editorial Jurídica de Chile.

Alessandri Rodríguez, A., Somarriva Undurraga, M. y Vodanovic Haklicka, A. (2004). Tratado de las obligaciones. (2a ed., Vol. 1). Santiago: Editorial jurídica de Chile.

Alvarado Mualme, M., Cortéz López, H., Cortés Solís, C., Duguet Vergara, R., Emilfork Orthusteguy, M., Muñoz Fuentes, I., Zuazo Echeñique, A. (2016). Sector financiero y Rev. derecho (Coquimbo, En línea) 2019, 26: e3589 
retail. En F. Barrientos Camus (Ed.), F. Fernández Ortega e I. Labra Saldías (Coords.). Muestrario de cláusulas abusivas (PDF). Santiago: Academia de derecho y consumo. Recuperado de https://bit.ly/2NzLQVI

Alvarado Uribe, Jorge Armando con Universidad Católica del Norte Coquimbo. $1^{\circ} \mathrm{Jdo}$ Policía Local de Coquimbo, 3-2013 (Corte de Apelaciones de La Serena 7 de junio de 2013). Recuperado de https://bit.ly/32Ypymi

Álvarez Moreno, M. (2000). El desistimiento unilateral en los contratos con condiciones generales. Madrid: Edersa.

Alvear Téllez, J. (2016). Consumidor y empresario: ¿relaciones jurídicas conflictivas? Hacia una concepción relacional del derecho del consumidor. Revista chilena de derecho, 43(3), 813-848, https://doi.org.10.4067/s0718-34372016000300003.

Baraona González, J. (2014). La regulación contenida en la ley 19.496 sobre protección de los derechos de los consumidores y las reglas del código civil y comercial sobre contratos: un marco comparativo. Revista chilena de derecho, 41(2), 381-408, https://doi.org/10.4067/S0718-34372014000200002.

Barrientos Camus, F. (2014). Una mirada al silencio y la aceptación en los contratos por adhesión con consumidores a partir del caso CENCOSUD. En su Condiciones generales de la contratación y cláusulas abusivas (Vol. 8, pp. 29-48). Santiago: Editorial Universidad Diego Portales.

Barrientos Camus, F. (2016). La modificación unilateral en los contratos de salud y televisión por cable. Criterios judiciales. En Departamento de Derecho Privado Universidad de Concepción (Ed.), M. Barría Paredes (Coord.), Estudios de derecho civil (Vol. 11, pp. 451-465). Santiago: Thomson Reuters.

Barrientos Zamorano, M. (2013). Artículo 3 b). Derecho a información veraz y oportuna. En Í. De la Maza Gazmuri y C. Pizarro Wilson (Dir.), F. Barrientos Camus (Coord.), La protección de los derechos de los consumidores (pp. 94-104). Santiago: Thomson Reuters.

Barros Bourie, E. (2012). Los contratos de servicios ante la doctrina general del contrato: la virtualidad analógica de las reglas del mandato. En F. Elorriaga de Bonis (Coord.), Estudios de derecho civil (Vol. 7, pp. 325-340). Santiago: Thomson Reuters.

Barros Vergara, C., Domínguez Riffo, F., Figueroa, F., Impellizzeri, R. y Portugal, D. (2016). Sector telecomunicaciones, streaming y video on demand. En I. Labra Saldías 
(Coord.). Muestrario de cláusulas abusivas (PDF). Santiago: Academia de derecho y consumo. Recuperado de: https://bit.ly/2owtZ9c

Beluche Rincón, I. (2009). El derecho de desistimiento del consumidor (Vol. 94). Valencia: Tirant lo Blanch.

Bercovitz Rodríguez-Cano, A. (1987). La defensa contractual del consumidor y el reparto de competencias entre el Estado y las comunidades autónomas en la doctrina del tribunal constitucional. En A. Bercovitz Rodríguez-Cano y R. Alberto y Bercovitz Rodríguez-Cano (Eds.), Estudios jurídicos sobre protección de los consumidores (pp. 7599). Madrid: Tecnos, pp. 75-99.

Bianca, C. (2007). Derecho civil. (F. Hinestrosa y E. Cortés, Trads.) (2a ed., Vol. 3). Bogotá: Universidad Externado de Colombia.

Biblioteca del Congreso Nacional de Chile. (2019). Historia de la Ley $N^{\circ} 20.555$. Recuperado de https://bit.ly/2qO0Jvd

Brantt Zumaran, M. y Mejías Alonzo, C. (2016). El derecho supletorio del contrato de servicios en el Código Civil chileno. Insuficiencia de las reglas del mandato y del arrendamiento. Revista de derecho (Valparaíso), (46), 71-103, https://doi.org/10.4067/s0718-68512016000100002.

Caprile Biermann, B. (2011). El desistimiento unilateral o renuncia: una especial forma de extinción de los contratos. En G. Figueroa Yáñez, E. Barros Bourie y M. Tapia Rodríguez(Coords.), Estudios de derecho civil (Vol. 6, pp. 271-296). Santiago: Abeledo Perrot.

Caprile Biermann, B. (2013). La ineficacia del mandato conferido por los clientes a las instituciones financieros para suscribir pagarés a su favor, antes y después del Sernac Financiero (autocontratación, irrevocabilidad y mandatos en blanco). En C. Domínguez Hidalgo, J. González Castillo, M. Barrientos Zamorano y J. Goldenberg Serrano (Coords.), Estudios de derecho civil (Vol. 8, pp. 232-255). Santiago: Thomson Reuters.

Cea Egaña, J. (1988). Tratado de la Constitución de 1980. Santiago: Editorial jurídica de Chile.

Celis Rodríguez, R. (1982). Normas especiales de arrendamiento de predios urbanos: ley $N^{\circ}$ 18.101. Santiago: Editorial jurídica de Chile.

Chile, Ministerio de Justicia. (1865). Código de comercio. Recuperado de http://bcn.cl/1 uu73 
La configuración del desistimiento del consumidor

Chile, Ministerio de Justicia. (2015). Código civil. Recuperado de http://bcn.cl/1uu74

Chile, Senado. (2011). Segundo informe de la comisión de economía, recaído en el proyecto de ley, en segundo trámite constitucional, que modifica la ley $\mathrm{N}^{\circ} 19.496$, sobre protección de los derechos de los consumidores, para dotar de atribuciones en materias financieras, entre otras, al Servicio Nacional del Consumidor, Boletín Nº994-03. Recuperado de https://bit.ly/2pf5nSP

Chile, Senado. (2011). Informe de las comisiones de economía y de hacienda, unidas, recaído en el proyecto de ley, en segundo trámite constitucional, que modifica la ley $N^{\circ} 19.496$, sobre protección de los derechos de los consumidores, para dotar de atribuciones en materias financieras, entre otras, al Servicio Nacional del Consumidor, Boletín N7094-03. Recuperado de https://bit.ly/2MVNBgc

Claro Solar, L. (2013). De las obligaciones (Vol. 5). Santiago: Editorial jurídica de Chile.

Córdova Bustos, G. (1960). Revocación de los actos jurídicos. Santiago: Universitaria.

Cornejo Aguilera, P. (2012). El contrato de arrendamiento de bienes raíces urbanos. Santiago: Thomson Reuters.

Cortez Matcovich, G. (2013). Artículo 50 E. La declaración de denuncia temeraria. En Í. De la Maza Gazmuri y C. Pizarro Wilson (Dir.), F. Barrientos Camus (Coord.), La protección de los derechos de los consumidores (pp. 1004-1008). Santiago: Thomson Reuters.

De la Maza Gazmurí, Í. (2004). El control de las cláusulas abusivas y la letra g). Revista chilena de derecho privado,(3), 35-67. Recuperado de https://bit.ly/2Pp3jC8

De la Maza Gazmuri, Í. (2006). El silencio de los inocentes: hacia una caracterización del deber de informar en sede precontractual. En J. Vargas Braun y S. Turner Saelzer (Coord.), Estudios de derecho civil (Vol. 1, pp. 128-177). Santiago: Lexis Nexis.

De la Maza Gazmuri, Í. (2007). ¿Llegar y llevar?: una mirada al crédito de las casas comerciales. Revista de derecho (Valdivia), 20(1), 61-84. https://doi.org/ 10.4067/s0718-09502007000100003.

De la Maza Gazmuri, Í. (2010). El suministro de información como técnica de protección de los consumidores: los deberes precontractuales de información. Revista de derecho (Coquimbo. En línea), 17(2), 21-52, http://doi.org/10.4067/S071897532010000200002. 
De la Maza Gazmuri, Í. (2013). Artículo $1^{\circ}$ № 3. Definición información básica comercial. En Í. De la Maza Gazmuri y C. Pizarro Wilson (Dir.), F. Barrientos Camus (Coord.), La protección de los derechos de los consumidores (pp. 23-31). Santiago: Thomson Reuters.

De la Maza Gazmuri, Í. (2013b). Artículo 1ํ№ 4. Definición publicidad. En Í. De la Maza Gazmuri y C. Pizarro Wilson (Dir.), F. Barrientos Camus (Coord.), La protección de los derechos de los consumidores (pp. 32-48). Santiago: Thomson Reuters.

Díez Picaza, L. (2008). De las relaciones obligatorias (6ª ed., Vol. 2). Madrid: Thomson Civitas.

Domínguez Águila, R. (2012). Teoría general del negocio jurídico. (2a ed.). Santiago: Editorial jurídica de Chile.

Espada Mallorquín, S. (2013). Artículo 4º. Irrenunciabilidad anticipada de derechos. En Í. De la Maza Gazmuri y C. Pizarro Wilson (Dir.), F. Barrientos Camus (Coord.), La protección de los derechos de los consumidores (pp. 194-200). Santiago: Thomson Reuters.

France. (2007). Code civil. Recuperado de http://bit.ly/2km2M6W

González Castillo, J. (2012). Mandatos irrevocables: Un cuestionamiento a su general aceptación. En F. Elorriaga de Bonis (Coord.), Estudios de derecho civil (Vol. 7, pp. 351360). Santiago: Thomson.

Hernández Paulsen, G. (2015). La obligación precontractual de la entidad financiera de informar al cliente, especialmente a la luz sobre protección de los derechos de los consumidores. En Á. Vidal Olivares, G, Severín Fuster y C. Mejías Alonzo (Eds.). Estudios de derecho civil (Vol. 10, pp. 351-373). Santiago: Thomson Reuters.

Intervalores Corredores de Bolsa Ltda. con Banco Bilbao Vizcaya Argentaria Chile, 113737-2016 (Corte de Apelaciones de Santiago 4 de enero de 2017). Recuperado de https://bit.ly/2Prrlws

Italia. (1942). II Codice Civile Italiano. Recuperado de http://bit.ly/2mMesBI

Klein, M. (1997). El desistimiento unilateral del contrato. Madrid: Civitas.

Larroumet, C. (1999). Teoría general del contrato. (J. Guerrero R., Trad.) (Vol. 1). Santa Fe de Bogotá: Temis. 
Ley 18.101, de 07 de enero de 1982, Fija normas especiales sobre arrendamiento de predios urbanos. Diario Oficial de la República de Chile, Santiago, 29 de enero de 1982. Recuperado de http://bcn.cl/1 uv61

Ley 19.496, de 07 de febrero de 1997, Establece normas sobre protección de los derechos de los consumidores. Diario Oficial de la República de Chile, Santiago, 07 de marzo de 1997. Recuperado de http://bcn.cl/1 uvuj

Ley $\mathrm{N}^{\circ}$ 16/2011, de 24 de junio, de contratos de crédito al consumo. Boletín Oficial del Estado, Madrid, España, 25 de junio de 2011. Recuperado de https://bit.ly/2WnFhcg

López Santa María, J. (2010). Los contratos. Santiago: Abeledo Perrot.

María Teresa García Vallejo contra Compañía de Seguros Penta Vida (M), 19417-2013 (Corte de Apelaciones de Concepción 19 de junio de 2014). Recuperado de https://bit.ly/2WljvpC

Momberg Uribe, R. (2013). Derecho del consumo. Revista chilena de derecho privado, (20), 245-253, https://doi.org/10.4067/s0718-80722013000100012.

Momberg Uribe, R. (2014). Las cláusulas de modificación unilateral en los contratos de consumo. En F. Barrientos Camus (Coord.). Condiciones generales de la contratación y cláusulas abusivas (Vol. 8, pp. 171-188). Santiago: Universidad Diego Portales. Recuperado de: https://bit.ly/3462Clh

Momberg Uribe, R. y Pizarro Wilson, C. (2013). Artículo 16 g). La buena fe y el equilibrio contractual. En Í. De la Maza Gazmuri y C. Pizarro Wilson (Dir.), F. Barrientos Camus (Coord.), La protección de los derechos de los consumidores (pp. 340-351). Santiago: Thomson Reuters.

Nasser Olea, M. (2013). Artículo 12. Obligación de respetar términos, condiciones y modalidades. En Í. De la Maza Gazmuri y C. Pizarro Wilson (Dir.), F. Barrientos Camus (Coord.), La protección de los derechos de los consumidores (pp. 257-264). Santiago: Thomson Reuters.

Nicolás Fischman Rajii con Banco BBVA, 85485-2016 (Corte de Apelaciones de Santiago 26 de septiembre de 2016). Recuperado de https://bit.ly/2WmM9GV

Peñailillo Arévalo, D. (2003). Las obligaciones. Santiago: Editorial jurídica de Chile. 
Piedrabuena Richard, G. (1972). La nueva ley de arrendamientos: historia y análisis de las modificaciones a la ley 17.600 a la ley 11.622. Santiago: López Viancos.

Pinochet Olave, R. (2013). Artículo $3^{\circ}$ bis. En Í. De la Maza Gazmuri y C. Pizarro Wilson (Dir.), F. Barrientos Camus (Coord.), La protección de los derechos de los consumidores (pp. 166-182), Santiago: Thomson Reuters.

Pizarro Wilson, C. (2007). ¿Puede el acreedor poner término unilateral al contrato?. Ius et praxis, 13,(1),11-28, http://doi.org/10.4067/S0718-00122007000100002.

Pizarro Wilson, C. y Pérez López, I. (2013). Artículo 17. Redacción de los contratos de adhesión. En Í. De la Maza Gazmuri y C. Pizarro Wilson (Dir.), F. Barrientos Camus (Coord.), La protección de los derechos de los consumidores (pp. 359-363). Santiago: Thomson Reuters.

Pizarro Wilson, C. y Petit Pino, J. (2013) Artículo 16 a). Facultad de dejar sin efecto, modificar a su solo arbitrio, o suspender unilateralmente la ejecución del contrato. En Í. De la Maza Gazmuri y C. Pizarro Wilson (Dir.), F. Barrientos Camus (Coord.), La protección de los derechos de los consumidores (pp. 305-311). Santiago: Thomson Reuters.

Prado López, P. (2013). Artículo 30 bis. el derecho a retracto. En Í. De la Maza Gazmuri y C. Pizarro Wilson (Dir.), F. Barrientos Camus (Coord.), La protección de los derechos de los consumidores (pp.151-165). Santiago: Thomson Reuters.

Proyecto Ley de 3 agosto de 2010, Modifica la Ley N²19.496, sobre Protección de los Derechos de los Consumidores, para dotar de atribuciones en materias financieras, entre otras, al Servicio Nacional del Consumidor. Boletín N 7094-03. Recuperado de https://bit.ly/36kBCRg

Rodríguez Guitián, A. (2001). El desistimiento en el contrato de servicios de los profesionales liberales, Anuario de derecho civil,54, (2), 681-751. Recuperado de: https://bit.ly/32QL3FS

Rosas Zambrano, M. (2014). Posibilidad de dejar sin efecto el contrato en la ley del consumidor. En En F. Barrientos Camus (Coord.), Condiciones generales de la contratación y cláusulas abusivas (Vol. 8, pp. 243-259). Santiago: Universidad Diego Portales. Recuperado de: https://bit.ly/3462Clh

San Martín Neira, L. (2013). Artículo 17 B g). Especificación de mandatos otorgados en virtud de contratos de adhesión de productos financieros. En Í. De la Maza Gazmuri y 
C. Pizarro Wilson (Dir.), F. Barrientos Camus (Coord.), La protección de los derechos de los consumidores (pp. 399-411). Santiago: Thomson Reuters.

Servicio Nacional del Consumidor con Cencosud Administradora de Tarjetas S.A., 12355-2011, CL/JUR/880/2013 (Corte Suprema 24 de abril 2013). Recuperado de Westaw- Thomson Reuters.

Servicio Nacional del Consumidor con Corporación Universidad de Aconcagua (UAC), 188-2013 (Corte de Apelaciones de Valparaíso 22 de mayo de 2013). Recuperado de https://bit.ly/2JweFAq

Severín Fuster, G. (2015). Sobre el modelo de contratación de servicios remunerados en el Derecho romano. Revista de derecho (Coquimbo. En línea), 22(2), 357-389, https://doi.org/10.4067/S0718-97532015000200012.

Severín Fuster, G. (2017). El desistimiento del cliente en los contratos de servicio: un derecho ad nutum. Bases normativas en el Código Civil chileno. En H. Corral Talciani y P. Manterola Domínguez, (Eds.), Estudios de derecho civil (Vol. 12, pp. 375-387). Santiago: Thomson Reuters.

Stitchkin Branover, D. y Figueroa Yáñez, G. (2012). El mandato civil. (5a ed.). Santiago: Editorial jurídica de Chile.

Tapia Rodríguez, M. (2014). Silencio y aceptación del consumidor. En F. Barrientos Camus (Coord.). Condiciones generales de la contratación y cláusulas abusivas. (Vol. 8, pp. 49-68). Santiago: Universidad Diego Portales. Recuperado de: https://bit.ly/3462Clh

Virgilio Cartoni Maldonado y otros con Banco Bilbao Vizcaya Argentaria Chile, 104748-2016 (Corte de Apelaciones de Santiago10 de enero de 2017). Recuperado de https://bit.ly/2Juc0ay

Zaldívar Larraín, A. (1958). Ley de arrendamiento: comentarios y jurisprudencia. Santiago: Editorial jurídica de Chile.

\section{Para citar este artículo bajo Norma APA 6a ed.}

Barrientos Camus, F. y De la Maza Gazmuri, Í. (2019). La configuración del desistimiento del consumidor. Revista de Derecho (Coquimbo. En línea), 26, e3589, https://doi.org/10.22199/issn.07189753-2019-0008 